Doctora en historia por la Houston University. Profesora de historia mexicana en San Diego State University. Entre sus publicaciones destacan: "Dangerous Minds: Changing Psychiatric Views of the Mentally IIl in Porfirian Mexico, 1876-1911", Journal of the History of Medicine and Allied Sciences, núm. 56, vol. 1, 2001; "The Criminalization of The Syphilitic Body. Prostitutes, Health Crimes, and Society in Mexico, 1867-1930" en Carlos Aguirre y Gilbert Joseph (coord.), Law, Crime, and Punishment in Latin American History. Selected Essays, Duke University Press, Durham, 2001; "Becoming Mad in Revolutionary Mexico. Mentally Ill Patients at the General Insane Asylum, Mexico 1910-1930" en Roy Porter y David Wright (coords.), The Confinement of the Insane. International Perspectives, Oxford University Press, en prensa; Nadie me verá llorar, Tusquets/Andanzas, México, 2001.

\section{Resumen}

El artículo explora características sobresalientes de la vida cotidiana del Manicomio General de $\mathrm{La}$ Castañeda. Se arguye que las rutinas médicas y sociales desarrolladas en el manicomio, muestran el papel fundamental tanto de las visiones de control social, como de las preocupaciones médicas. Confirmando los descubrimientos de la literatura revisionista, el artículo cuestiona la validez de interpretaciones que describían al manicomio únicamente como una institución totalitaria. Se hace hincapié en la relativa debilidad del Estado para establecer políticas de salud pública aun a niveles locales, durante la era posrevolucionaria temprana. En este sentido, el artículo se une a estudios recientes de la historiografía del México moderno que buscan documentar la formación del Estado desde sus raíces más cotidianas.

Palabras clave:

Salud mental, tratamiento psiquiátrico, manicomio, posrevolución, México.

\section{Abstract}

This article explores major features of daily life inside at the General Insane Asylum La Castañeda. The paper argues that the medical and social routines developed at La Castañeda show that both visions of social control and concerns with medical care played a major role. Much in accordance with findings of revisionist literature, this article questions the validity of claims that pictured the insane asylum solely as a totalitarian institution. In doing so, the article highlights the relative weakness of the post-revolutionary state to enforce policies of public health even at local levels during the first three decades of the twentieth century. This article thus adds to recent studies in modern Mexican historiography searching to document the formation of state at the most basic, day to day level.

Key words:

Mental health, psychiatric treatment, insane asylum, post-revolution, Mexico.

Artículo recibido:

agosto de 2000

Aceptado en su versión final:

noviembre de 2000 


\title{
Por la salud mental de la nación: vida cotidiana y Estado en el Manicomio General de La Castañeda, México 1910-1930
}

\author{
Cristina Rivera-Garza
}

$\mathbf{E}$ n 1917, cuando el doctor Agustín Torres escribió un par de artículos describiendo las condiciones de vida dentro del Manicomio General, no sólo celebró los adelantos médicos y sociales llevados a cabo dentro de las instalaciones psiquiátricas sino que también llamó la atención sobre el papel privilegiado de esta institución en el proceso de reconstrucción nacional. En búsqueda de mayor presupuesto y más atención gubernamental, el también director general de la institución de salud mental mantuvo que el manicomio era un centro estratégico para crear las mentes que el nuevo país necesitaría. ${ }^{1}$ Aunque dramática y acaso altisonante, esta declaración no debió haber resultado inusual para aquellos interesados en temas psiquiátricos. De hecho, unos 21 años atrás, los miembros del comité para la construcción del Manicomio General manifestaron aspiraciones de similar envergadura en el informe que presentaron ante el "Congreso Médico PanAmericano" de 1896. En este documento, el comité reconocía que "la lo-

1 Torres, "Manicomio", 1917, pp. 30-32. cura es una condición que carece de una marca característica o estable" por lo que, de pasar inadvertida o de ser mal diagnosticada, presentaba especiales peligros para la sociedad en su conjunto. ${ }^{2}$ Por esta razón, los médicos, abogados, ingenieros y burócratas a cargo del proyecto veían al manicomio como una herramienta social más que individual, como una misión más que una tarea. Por esa misma razón, se percibían a sí mismos no sólo como guardianes de la salud mental de la comunidad, sino también como campeones del orden social.

Esta mentalidad permeó la planeación y la construcción del Manicomio General, un complejo monumental que abarcó 25 edificios rodeados de amplios bosques y elegantes jardines localizado en Mixcoac, una población en el sur de la creciente metrópolis donde miembros de la elite vacacionaban los fines de semana. ${ }^{3}$ Conocido popularmente por el nombre de la ex hacien-

${ }^{2}$ Morales y Romero, “Exposición”, 1898, pp. 888-896.

3 Para una historia social y cultural del Manicomio General de La Castañeda, ver RiveraGarza, Mad. 
da en donde se ubicó - La Castañeda-, el manicomio provocó mucha curiosidad y, a veces, hasta aprehensión, entre los vecinos del lugar. ${ }^{4}$ Aunque alguna escapada estudiantil o esporádicos recuentos periodísticos contribuyeron a dar a conocer el mundo interior de la institución, éstos poco hicieron para disminuir el morbo y el misterio que la rodeaba. En efecto, la rutina diaria de los que ahí vivían o trabajaban permaneció oculta para el público en general. Basado en documentos oficiales, reportes de inspectores de la Beneficencia Pública, y expedientes médicos, este artículo intenta develar los procesos tanto institucionales como cotidianos que dieron vida a este establecimiento público durante los últimos momentos del porfiriato y los primeros años del proceso revolucionario. ${ }^{5}$ Inaugurado el primero de septiembre de 1910 y construido con fondos de la Beneficencia Pública, el manicomio es tal vez uno de los mejores ejemplos de las estrategias de modernización que caracterizaron los últimos años de régimen de Porfirio Díaz ya que, ahí, un selecto grupo de expertos comisionados por el Estado no solamente usó su conocimiento de lenguajes y teorías médicas, sino también su flagrante preocupación por el orden social de la comunidad y de la nación en general. Puesto que a unos meses de su apertura dio inicio el movimiento revolucionario, el manicomio también constituye una arena pri-

\footnotetext{
4 Para una historia oral de Mixcoac, véase Pensado y Correa, Mixcoac, 1996.

5 Basado en investigación realizada en el Archivo Histórico de la Secretaría de Salubridad y Asistencia (en adelante AHSSA).
}

vilegiada para detectar los alcances y límites de las políticas de salud pública esbozadas por los nacientes regímenes posrevolucionarios. Más que el análisis del antes y el después, lo que resulta de especial importancia en este aspecto son los años de negociación e inestabilidad que precedieron a la reforma administrativa y médica que se llevó a cabo en 1929, el año en que las autoridades del manicomio y de la Beneficencia Pública intentaron cambiar la faz y el destino de la institución en su conjunto.

El Manicomio General fue resultado de un proyecto estatal que se elaboró lentamente y no sin tropiezos durante un periodo de 26 años. ${ }^{6}$ Entre 1884, cuando el médico Román Ramírez presentó por primera vez información sistemática acerca del manejo tanto médico como administrativo de manicomios en varias naciones extranjeras, y julio de 1910 , cuando el hijo del presidente, el ingeniero Porfirio Díaz, completó los trabajos de construcción de la institución, se llevó a cabo un debate significativo entre los encargados de realizar este proyecto.?

${ }^{6}$ Un análisis detallado de este proceso se encuentra en Rivera-Garza, "Architecture", manuscrito.

7 Ramírez, Manicomio, 1884. El interés de Ramírez por aspectos legales relacionados con la salud mental también se desarrolló en su Resumen, 1901. Para información sobre la participación de Porfirio Díaz, hijo, en este proyecto, véase "Contrato celebrado entre la secretaría de Gobernación y el señor ingeniero don Porfirio Díaz, hijo, para la construcción del Manicomio General", en AHSSA, FBP (Fondo de la Beneficencia Pública), SEH (Serie Establecimientos Hospitalarios), SeMG (Sección Manicomio General), leg. 49, exp. 2. 
El debate fundamentalmente incluyó preocupaciones de tipo médico, pero no dejó de lado ansiedades sociales. En una ciudad cuya población crecía a una velocidad vertiginosa, dentro de un país comprometido con procesos de industrialización a toda costa, los profesionales que crearon La Castañeda estaban al tanto de la relevancia psiquiátrica de la institución, pero nunca olvidaron el peso social que ésta conllevaba. ${ }^{8}$ En un acuerdo tácito con el periodista y poeta Manuel Gutiérrez Nájera, los miembros del comité interpretaban las paredes que rodeaban La Castañeda como una frontera que separaba a "los buenos y aptos" de los "débiles y corruptos", una preocupación políticamente significativa entre comentaristas sociales adeptos a hablar sobre los pobres, las mujeres, los mestizos y los indios en términos de amenaza social. ${ }^{9}$ Así pues, convencidos de su misión modernizadora, los encargados de diseñar el manicomio entendían la reclusión hospitalaria como una forma de proveer tratamiento médico a los enfermos mentales y, concomitantemente, como una manera de controlar a miembros de la sociedad que podían ser potencialmente peli-

8 Un análisis de la historia urbana de la ciudad de México es Rodríguez, Experiencia, 1987. También Johns, City, 1997.

9 Gutiérrez, "Pobrecito", 1972, p. 19. Éste y otros artículos fueron publicados originalmente en el periódico El Universal entre 1883 y 1895. La mentalidad punitiva porfiriana también se encuentra en los escritos alrededor de la criminalidad. Los más significativos entre ellos son: Guerrero, Génesis, 1901; Roumagnac, Criminales, 1904; Macedo, Criminalidad, 1897. grosos. ${ }^{10}$ Estas visiones de control social, sin embargo, iban mano en mano con descripciones del manicomio como un lugar de refugio donde los más pobres y los más débiles podrían asegurar cuidado médico o de custodia según fuera el caso o la necesidad. ${ }^{11}$ Aunque contradictorio en apariencia, el manicomio pudo ofrecer este doble programa de asistencia y control por un periodo muy corto. Tan pronto como se dio inicio a la lucha revolucionaria, el hospital enfrentó serias limitaciones financieras. En lugar de convertirse en un moderno establecimiento de tratamiento e investigación psiquiátrica, el manicomio se transformó rápidamente en un lugar periférico donde poco personal sin mucho entrenamiento especializado tenía grandes dificultades en tratar a más internos de los esperados, muchos de ellos sufriendo condiciones crónicas. Las autoridades del manicomio trataron de rescatar el proyecto de salud mental en varias ocasiones, ya fuera solicitando más fondos para asegurar su funcionamiento o acentuando el orden producido por el Reglamento Interno de 1913, pero la prensa amari-

10 Una selección representativa de interpretaciones de manicomios como instituciones de control social incluye a: Foucault, Madness, 1965; Goffman, Asylums, 1961; Rothman, Discovery, 1980; Szaz, Myth, 1961.

${ }^{11}$ A medida que crece la investigación histórica de manicomios, las interpretaciones se han hecho más complejas. Una selección representativa de la literatura revisionista incluye: Dawyer, Homes, 1987; Grob, Mental, 1973; Digby, Madness, 1985; Bachrach, "Asylum", 1984, pp. 975 978; Goldberg, Sex, 1999; Sadowsky, Imperial, 2000. 


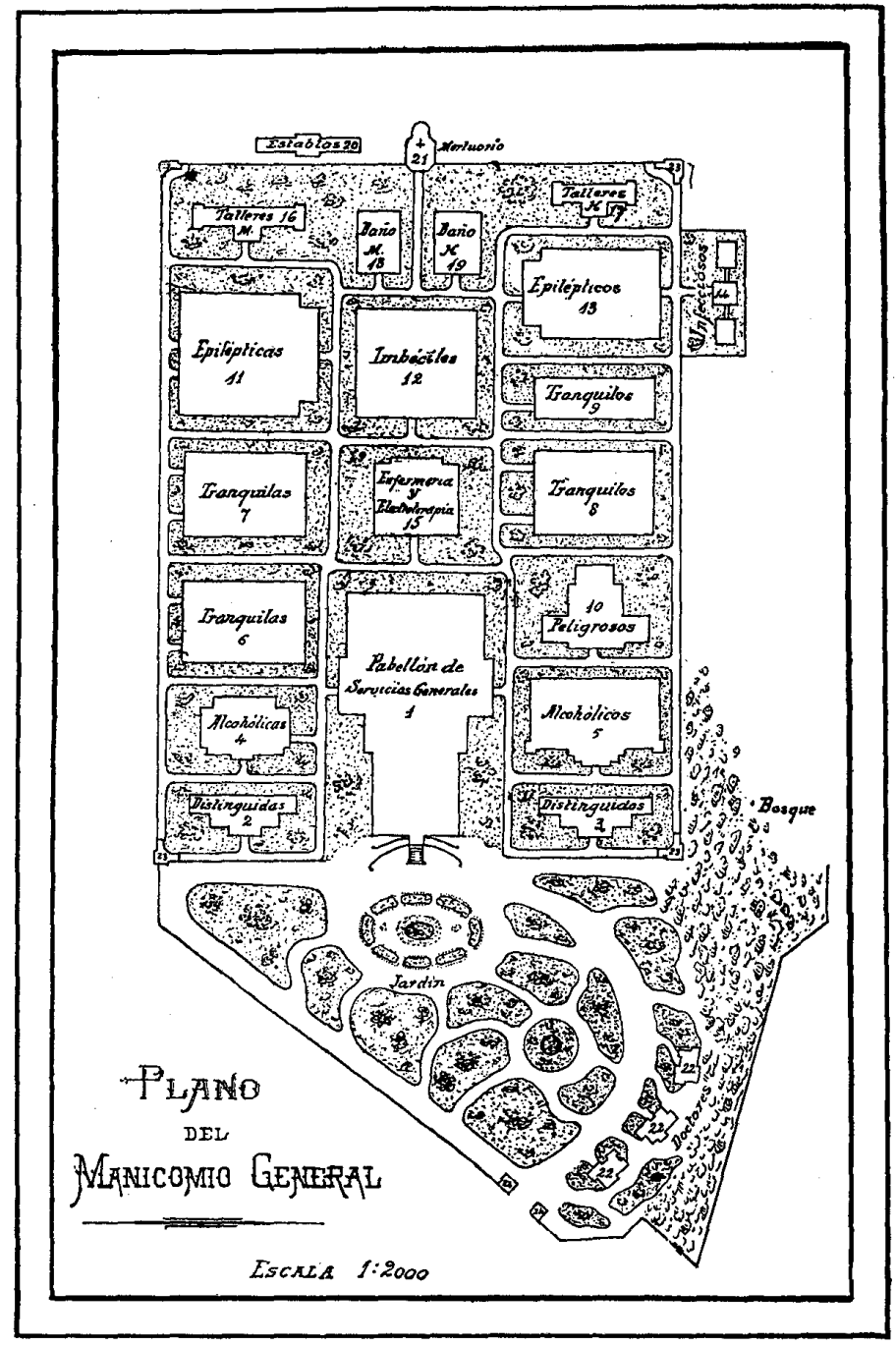

Plano del Manicomio General donde se aprecia la distribución de los pabellones en tres ejes longitudinales y las áreas verdes que los rodeaban, 1910.

Genaro García, Crónica oficial de las fiestas del primer centenario de la independencia de México, talleres del Museo Nacional, 1911, p. 111. 
llista de la época no dejó escapar ocasión alguna para publicar artículos donde el manicomio, más que institución de salud, parecía una cárcel custodiada por personajes de una crueldad legendaria.

Entre la leyenda negra de La Castañeda y las descripciones oficiales, acaso demasiado benignas, se desarrolló sin embargo una realidad más compleja y más dinámica. Evadiendo ambos extremos, este artículo investiga la rutina cotidiana que psiquiatras, burócratas e internos crearon en los pabellones del Manicomio General. Se sostiene aquí que, en una cercanía tensa y activa, estos personajes negociaron sus conocimientos y experiencias, sus idiosincrasias, para formar la realidad de la locura y sus tratamientos en el México moderno. Así, juntos, presenciaron el nacimiento de uno de los proyectos más caros del porfiriato y, juntos también, experimentaron su rápida caída y urgente reformación en el México posrevolucionario. Al abrir las puertas del manicomio, una tarea pocas veces intentada en la historiografía de la región, este artículo primero explora los efectos de orden producidos por el reglamento interno. ${ }^{12}$ Se trata, en primera instancia, pues, de un breve recuento

12 Estudios históricos de práctica psiquiátrica en Latinoamérica incluyen: Farmer, "Birth", 1992; Ruiz, Psiquiatras, 1994; Plotkin, "Freud," 1997, pp. 45-74. En el caso de México y, más precisamente de La Castañeda, varios psiquiatras han realizado esta labor de revisión institucional, ver, entre orros, Ruiz y Morales, Heinen, "Primeros", 1996, vol. 1, pp. 124-129; Calderón, "Notas", 1996, vol. 1, pp. 198-207. del marco institucional del establecimiento. Una vez dentro, el texto describe la rutina diaria de doctores y pacientes, tratando de resaltar los límites de orden oficial que especialistas y abogados crearon de manera más bien ferviente. La vida cotidiana no era sencilla al inicio del siglo xx y esto fue especialmente cierto para los internos del manicomio. A medida que se desarrollaban las batallas revolucionarias y las condiciones internas empeoraban, resultó cada vez más claro que, contrario de lo que arguyen los que ven a los manicomios únicamente en términos de control social, el manicomio no podía reproducir, y mucho menos reforzar, las ideas prevalecientes de orden. De hecho, la creciente problemática interna del manicomio ilustró dramáticamente el límite de las aspiraciones institucionales y, luego entonces, la relativa debilidad del Estado revolucionario para instaurar políticas públicas aun a escala local. Esta investigación, pues, se incorpora al creciente número de trabajos que, al explorar la formación del Estado desde su raíz más cotidiana, ponen en tela de juicio la centralización inmediata y efectividad represiva de los regímenes posrevolucionarios. ${ }^{13}$ Viendo agencia en actores sociales usualmente vituperados, como los enfermos mentales, e importancia política en instituciones claramente periféricas, tales como el manicomio, este artículo busca trazas de esa modernidad tan prometida como evasiva en lugares poco comunes pero no

${ }^{13}$ Un ejemplo de esta corriente es Joseph y Nugent, Everyday, 1994. 
menos reales. Lo hace, además, tratando de remarcar los elementos más anodinos de la vida diaria, la serie de pequeños rituales cotidianos que, por obvios, muchas veces pasan inadvertidos. Así pues, en lugar de otorgar papeles defínidos a los distintos actores que convivían en La Castañeda -ya sea como víctimas o como victimarioseste artículo intenta mostrarlos en su quehacer regular, ahí donde el poder y la falta de poder se entrelazaron para crear estrategias de sobrevivencia y no principios dogmáticos. ${ }^{14}$ En este aspecto, el presente artículo se incorpora al creciente número de historias sociales que se han ido produciendo sobre la vida en reclusión a nivel mundial. ${ }^{15}$ Como en esos trabajos, el artículo trata de no perder de vista el contexto en el cual se construyeron los muros que definieron el adentro y el afuera. Más que mera metáfora, pues, el surgimiento y la desaparición del Manicomio General ejemplifica el alcance y los límites de los proyectos modernizadores de inicios de siglo.

${ }^{14}$ Los conceptos de "estrategias móviles de poder" y "múltiples focos de resistencia" de $\mathrm{Mi}$ chel Foucault han sido de particular utilidad en esta interpretación. Véase Foucault, Historia, 1978, pp. 92-102.

15 Éste es el caso del volumen editado por Wright y Porter, Confinement, 2000, en el cual se incluyen ensayos sobre manicomios en Australia, Inglaterra, Francia, Sudáfrica, Suiza, Canadá, Alemania, Japón, Argentina y México. También ilustrativo en este aspecto es Sadowsky, Imperial, 2000.
TOMA I: LA ADMINISTRACIÓN DE LA SALUD MENTAL -EL MARCO INSTITUCIONAL

De la misma manera en que la ubicación del manicomio en la periferia de la ciudad contribuyó a la creación de un orden urbano moderno, las autoridades de la Beneficencia Pública buscaron la reproducción de ese orden en el interior del establecimiento. Con ese fin, un inspector de la Beneficencia y cinco directores de diversos hospitales públicos redactaron el reglamento interno del lugar -un documento que reunió las reglas de trabajo y conducta social que regirían el establecimiento. ${ }^{16}$ Como es el caso con este tipo de documentos, más que reflejar lo que acontecía al interior del manicomio, éste nos ofrece una visión de lo que las autoridades creían funcional y efectivo. Así entonces, más que un recorrido por las instalaciones del manicomio, esta primera introducción a la rutina diaria de La Castañeda es, pues, una exploración dentro de la mentalidad de las autoridades de salud pública para quienes la salud mental constituía un bien nacional.

Oficialmente reconocido como hospital y asilo, La Castañeda se construyó para proveer tratamiento médico y cuidado de custodia a todos los enfermos mentales sin distinción de sexo, edad, nacionalidad o religión. ${ }^{17}$ En tanto institución pública, el manicomio estuvo bajo la jurisdicción de la

16 "Reglamento interior del establecimiento", 1913, en AHSSA, FBP, SEH, SeMG, leg. 3, exp. 25.

17 Ibid., p. 2. 
Beneficencia Pública, la cual dependía a su vez de la Secretaría de Gobernación. A través de esta oficina, el gobierno nombraba al "personal científico y administrativo", es decir, médicos de tiempo completo y administradores cuyo salario anual excediera los 600 pesos, coadyuvando a incrementar los lazos entre el Estado y el manejo de la salud mental en México.

A nivel "científico", el Estado contribuyó a la profesionalización de la psiquiatría al designar doctores a las posiciones más importantes de la institución, entre las cuales se encontraba la de director general. Replicando el modelo francés, las autoridades mexicanas también apoyaron la transformación del asilo en instituto de entrenamiento académico cuando permitieron que doctores enseñaran sus clases de psiquiatría en sus instalaciones, sobre todo para "cooperar con la Escuela Nacional de Medicina y la enseñanza de esta disciplina". ${ }^{18} \mathrm{La}$ instauración de un museo patológico y un departamento de investigación miscroscópica aumentaron la reputación científica del establecimiento. ${ }^{19}$

A nivel administrativo, el Estado jugó un papel muy poderoso al nominar a los inspectores que, según el reglamento, podían visitar el manicomio "cualquier día y a cualquier hora" para supervisar "sus departamentos y dependencias, sus libros y archivos;

18 lbid. Un análisis de las relaciones entre manicomios e instituciones educativas en Francia es Goldstein, Console, 1987.

19 "Reglamento' interior del establecimiento", 1913, en AHSSA, FBP, SEH, SeMG, leg. 3, exp 25, p. 39. para preguntar por toda clase de información y reportes; para hablar con los empleados, pacientes y doctores". ${ }^{20} \mathrm{El}$ Estado también se dio a sí mismo el derecho de "comunicar al director general las instrucciones que crea necesarias para asegurar el buen orden del establecimiento y la efectividad de sus servicios". ${ }^{21}$ Así, validando a la psiquiatría como una disciplina legítima de la medicina y expandiendo el alcance burocrático del porfiriato, el Estado se convirtió en el verdadero guardián de la salud mental de la nación.

La administración del Manicomio General siguió estrategias usadas en instituciones extranjeras pero también adoptó mecanismos claramente locales. Por ejemplo, mientras que los hospitales creados en la época colonial -el San Hipólito y el Divino Salvador-contaban con un administrador residente y médicos visitantes, el nuevo manicomio quedó en manos de un doctor director que, de acuerdo con las reglas, debería residir en el lugar. Este funcionario estaba a cargo de nominar candidatos para las posiciones que después denominaría la Secretaría de Gobernación, y de contratar a todos los empleados que ganaran menos de 600 pesos anuales. 22 Como empleado de tiempo completo, se esperaba que el doctor director dedicara toda su energía y conocimiento a mejorar el tratamiento de los enfermos y a incrementar el prestigio de la institución. El doctor José Meza Gutiérrez, profesor de psiquiatría en la Escuela Nacional

\footnotetext{
${ }^{20}$ Ibid., p. 2.

${ }^{21}$ Ibid., p. 3.

22 Ibid., p. 56.
} 
de Medicina, ocupó esta posición en 1910.23

La segunda posición más importante en el manicomio le correspondía a un administrador contador que también residiría en el lugar y estaría a cargo de elaborar el presupuesto de la institución, supervisar a los empleados, y escribir reportes mensuales para la Beneficencia Pública. ${ }^{24}$ Se esperaba de él que visitara frecuentemente los distintos departamentos, manteniendo un ojo vigilante sobre las rutinas diarias de empleados y pacientes. Además, este funcionario establecería y supervisaría a los empleados administrativos de rangos menores, como el jefe de cocina o de ropería. Aunque oficialmente bajo las órdenes del doctor director, el administrador recibiría un salario mayor al de aquél -300 y 240 pesos al mes respectivamente. ${ }^{25}$ En 1910 , esta posición le fue concedida a Luis García, un doctor de prestigio reconocido y responsable de la transformación del hospital privado Casa de Salud Rafael Lavista en un establecimiento psiquiátrico. ${ }^{26}$ Un guardia general ayudaría al administrador en sus múltiples actividades por 99 pesos al mes, un salario comparable al de un jefe médico. ${ }^{27}$

La tercera oficina administrativa en importancia dentro de La Castañeda

\footnotetext{
23 Buentello, "Orígenes", 1936, s.n.

24 "Reglamento interior del establecimiento", 1913 en AHSSA, FBP, SEH, SeMG, leg. 3, exp. 25, p. 58.

25 "Presupuestos", 1910, en AHSSA, FBP, SEH, SeMG, leg 2, exp.6, p. 1.

${ }^{26}$ Buentello, "Orígenes", 1936.

27 "Presupuestos", 1910, en AHSSA, FBP, SEH, SeMG, leg. 2, exp. 6, p. 1.
}

era el departamento de admisiones. El jefe de esta sección, también un empleado residente, coleccionaría, examinaría y archivaría los documentos requeridos para aceptar internos. ${ }^{28}$ Después de ser admitidos, este funcionario estaba a cargo de elaborar y mantener los expedientes de los internos, los que usualmente contenían una forma de admisión, certificados médicos, pases de transferencias, permisos de salida, cartas, fotografías, y cualquier otro documento relacionado con la estancia del interno en el manicomio. Gracias al jefe de admisiones, la institución contó con un archivo bien organizado. Además, él informaría a los parientes o tutores que así lo requirieran sobre el estado de salud de los internos, una tarea que se llevaba a cabo ya fuera por telégrafo o correo. Permaneciendo en su oficina de siete de la mañana a una de la tarde, y de tres a ocho de la noche, y forzado a trabajar tiempo extra si esto era necesario, el jefe de admisiones ganaría un salario de 99 pesos al mes. ${ }^{29}$

Mientras que los administradores eran funcionarios poderosos en el manicomio, los doctores eran los que le daban su identidad como una institución moderna y científica. Contrario a los hospitales construidos en la época colonial, La Castañeda contrató a once doctores, 30 enfermeros y enfermeras, y 96 asistentes hombres para cuidar a los internos, un aspecto que coadyuvó

28 "Reglamento interior del establecimiento", 1913, en AHSSA, FBP, SEH, SeMG, leg. 3, exp. 25 , pp. 52-55.

29 "Presupuestos", 1910, en AHSSA, FBP, SEH, SeMG, leg. 2, exp. 6, p. 1. 
con los objetivos terapéuticos del manicomio. ${ }^{30} \mathrm{~A}$ pesar de que los doctores no tenían que ser psiquiatras, la mayoría usaba la experiencia en La Castañeda para terminar una especialización en el área. El personal médico fue organizado de acuerdo con una jerarquía que colocaba al doctor director en el punto más alto, seguido del jefe de residentes, quienes ganaban un salario de 120 pesos mensuales y supervisaban a dos médicos residentes cuyo salario era de 90 pesos para cada uno. Los jefes de los departamentos de hombres y de mujeres, quienes se hacían acreedores a un salario de 99 pesos mensuales, supervisaban a cinco doctores externos que ganaban 75 pesos respectivamente. Un dentista, con el salario de 60 pesos mensuales, también estaba incluido en el personal médico de La Castañeda. ${ }^{31}$ Aun cuando los jefes de departamento llevaban a cabo tareas médicas, sus responsabilidades eran mayormente burocráticas. Así entonces, el cuidado de los casi 1000 internos recaía sobre los residentes y los doctores externos, siete médicos en total. ${ }^{32}$ Ellos estaban asignados a pabellones específicos dentro de los cuales tanto el personal de

30 Ibid., p. 1. La mayoría de los puestos fueron ocupados por médicos, sin embargo en 1915 el manicomio contrató a una doctora. Se trató de Rosario M. Ortiz quien primero trabajó como externa $\mathrm{y}$, meses después, como residente. Véase "Relación de personal de 1914 a 1915", en AHSSA, FBP, SEH, SeMG, leg. 4, exp. 23, pp. 2-3.

31 Ibid., p. 1.

32 El número de doctores residentes y externos era, para 1915, de 5 y 12 respectivamente. Véase "Relación de personal, 1914-1915", en AHSSA, FBP, SEH, SeMG, leg. 4, exp. 23. apoyo como los pacientes quedaban bajo su total responsabilidad. Si bien únicamente los residentes vivirían dentro del manicomio, todos los doctores tenían que usar un reloj especial para dejar constancia de su entrada a las siete de la mañana, la hora en que las actividades daban inicio oficialmente. ${ }^{33}$

De acuerdo con el reglamento interno, la rutina diaria de los doctores empezaría con el examen de los internos, aun aquellos que se consideraran incurables. ${ }^{34}$ Mientras se preparaban para dar tratamientos médicos, ya sea higiénico, farmacológico, quirúrgico, eléctrico, psicológico o restrictivo, los doctores leían la ordenanza -un documento que contenía información sobre la identidad del paciente así como también su diagnóstico, tratamiento y medicinas prescritas. Tan pronto como terminaba el examen y si los doctores lo juzgaban conveniente, nuevas medicinas se ordenaban de la farmacia principal, la única fuente de drogas en el manicomio. Cuando los internos requerían cirugía, los doctores tendrían que autorizar su transferencia a la enfermería y, eventualmente, al cuarto de operaciones. Como para todo movimiento de pacientes dentro de las instalaciones hospitalarias, esta actividad requería un permiso escrito por el doctor en turno. En caso de que el doctor dictaminara el uso de métodos restrictivos, tales como la camisa de fuerza, el permiso era también indispensable.

33 "Presupuestos", 1910, en AHSSA, FBP, SEH, SeMG, leg. 2, exp. 6, pp. 22-23.

34 "Reglamento interior del establecimiento", 1913, en AHSSA, FBP, SeMG, leg. 3, exp. 25, pp. 18-22. 
Así, las rondas médicas concluían a las diez de la mañana. Mientras los doctores externos quedaban libres de salir del manicomio, los residentes que permanecían dentro, de acuerdo con un calendario previamente estipulado, se preparaban para llevar a cabo cirugías, para continuar con investigaciones personales, o para enseñar lecciones gratuitas a internos o enfermeros. ${ }^{35} \mathrm{~A}$ pesar de las muchas responsabilidades y los numerosos pacientes, las autoridades esperaban que el interés de los incipientes psiquiatras fuera en ascenso. Sabían, además, que La Castañeda era una de las pocas instituciones en donde los jóvenes estudiosos podrían encontrar entrenamiento práctico en el campo de su elección. La realidad, sin embargo, no siempre les dio la razón.

Una tarea de especial importancia entre los doctores de La Castañeda era la elaboración de las historias clínicas de los internos. Incluyendo

información acerca del pasado del paciente, su fotografía, una narración de los síntomas del interno, el diagnóstico, una descripción de la evolución de la enfermedad, el tratamiento y sus resultados y, finalmente, la fecha de salida o los resultados de la autopsia [...]

Estas historias pusieron de manifiesto las interpr xciones comunes sobre lo que era la enfermedad mental. ${ }^{36}$ A inicios de siglo, a medida que el número de pobres se acrecentaba en la ciudad provocando ansiedades en profesionales de la elite, estas interpretaciones psiquiátricas estuvieron profun-

$$
\begin{aligned}
& 35 \text { Ibid., p. } 25 . \\
& 36 \text { Ibid., p. } 24
\end{aligned}
$$

damente influidas por las teorías de la degeneración - un grupo de ideas articuladas primero por August Morel y Valentin Magnan que, en general, asociaban la locura con una carga hereditaria y un proceso degenerativo. ${ }^{37}$ Aunque la mayoría de los doctores escribían estas historias clínicas de manera aislada, las autoridades trataron de promover la colaboración médica, especialmente en casos de difícil diagnóstico. Sin embargo, en La Castañeda no existían las reuniones de trabajo tan comunes en otras instituciones psiquiátricas. Las clínicas, o clases de psiquiatría impartidas en el manicomio, eran el único foro formal durante estos años para discutir temas psiquiátricos, tales como la identificación de síntomas y la prescripción de tratamientos. ${ }^{38}$

El personal médico de La Castañeda también incluía enfermeros -de primera y segunda categoría- y asistentes o guardias. Porque su trabajo los colocaba en contacto cercano con los inter-

${ }^{37}$ Un estudio sobre los orígenes y el desarrollo de la teoría de la degeneración es Dowbiggin, Inberiting, 1991. Este autor describe la teoría de la degeneración como "a steady though not necessarily irreversible hereditary deterioration over the course of four generations...[Including] symptoms such as moral depravity, mania, mental retardation, and sterility. Physicians ascribed a variety of causes to degeneracy, including alcoholism, immorality, poor diet, and unhealthy domestic and occupational conditions. However, the principal cause of degeneracy that physicians cited was heredity". Un análisis de los usos de la teoría de la degeneración en Brasil es Borges, "Puffy", 1993, pp. 235-256.

38 "Reglamento interior del establecimiento" 1913, en AHSSA, FBP, SEH, SeMG, leg. 3, exp. 25, p. 42 . 
nos, estos trabajadores constituían una pieza fundamental en las aspiraciones médicas del manicomio. Sin embargo, la institución no requería que los enfermeros fueran certificados y los contrataban cuando las autoridades "los juzgaban aptos para el trabajo". ${ }^{39}$ Así, con un entrenamiento a todas luces sospechoso y recibiendo salarios bastante bajos, la institución demandaba de ellos una disciplina profesional a toda prueba y, aun, sacrificios personales. Por ejemplo, por un salario de $1.50 \mathrm{al}$ día, un enfermero de primera clase tendría que elaborar la ordenanza de cada interno; ordenar y recibir la comida; cambiar y limpiar la ropa de cama requerida; alimentar a los internos aun en contra de su voluntad; recibir, almacenar y administrar los medicamentos; facilitar instrumentos de escritura a los pacientes y enviar cartas de éstos a la oficina general; prevenir el paso de personas no autorizadas a los pabellones del lugar; escribir un reporte diario de sus actividades y, mientras tanto, usar extremo cuidado y benevolencia al tratar a los internos. ${ }^{40}$ Además de todas estas responsabilidades, y precisamente a causa de éstas, los enfermeros no podían dejar los pabellones " $n i$ siquiera para comer" hasta que otro empleado los reemplazara. ${ }^{41}$

Igualmente agotadoras y pobremente pagadas - ganaban un promedio de 70 centavos al día- eran las tareas de los guardias. Estos no solamente apoyaban el trabajo de los enfermeros, sino que también estaban a cargo del

\footnotetext{
39 Ibid., p. 62.

40 lbid., pp. $28-33$.

41 Ibid., p. 33.
}

cuidado personal de los internos a quienes debían "bañar, limpiar, vestir, alimentar, caminar dentro y fuera de los pabellones, controlar en caso de ataques violentos, y cuidarlos en general como si se tratara de niños". ${ }^{42}$ Debido a este contacto casi íntimo con los internos, los guardias se convirtieron en motivo de críticas que, de otra mane$\mathrm{ra}$, iban en realidad dirigidas a la institución como tal.

La mayoría de estos empleados de rango menor vivía y comía en las instalaciones del manicomio. Por esta razón, las autoridades del mismo crearon numerosas reglas para controlar su conducta social. ${ }^{43}$ Para empezar, de acuerdo con el reglamento interno, el acceso al lugar estaba fuertemente regulado, tanto como el movimiento interno de pacientes y empleados quienes, en la mayoría de los casos, requerían permisos especiales o visas firmadas por el doctor director. Las autoridades también prohibieron la interacción social entre empleados e internos, y especialmente entre los empleados mismos, sugiriendo que la comunicación personal se limitara a situaciones de trabajo y, aun así, que sólo se llevara a cabo "dentro de la decencia más extrema". ${ }^{44}$ De igual manera fueron desautorizadas las relaciones entre hombres

42 Ibid., p. 35.

${ }^{43}$ Hacia 1915, todos los empleados, excepto el doctor director, están registrados en las listas de desayunos, comidas y cenas del manicomio. Véase "Asuntos diversos de personal", 1915-1916, en AHSSA, FBP, SEH, SeMG, leg. S, exp. 9.

44 "Reglamento interior del establecimiento", 1913, en AHSSA, FBP, SEH, SeMG, leg. 3, exp. 25, p. 65. 


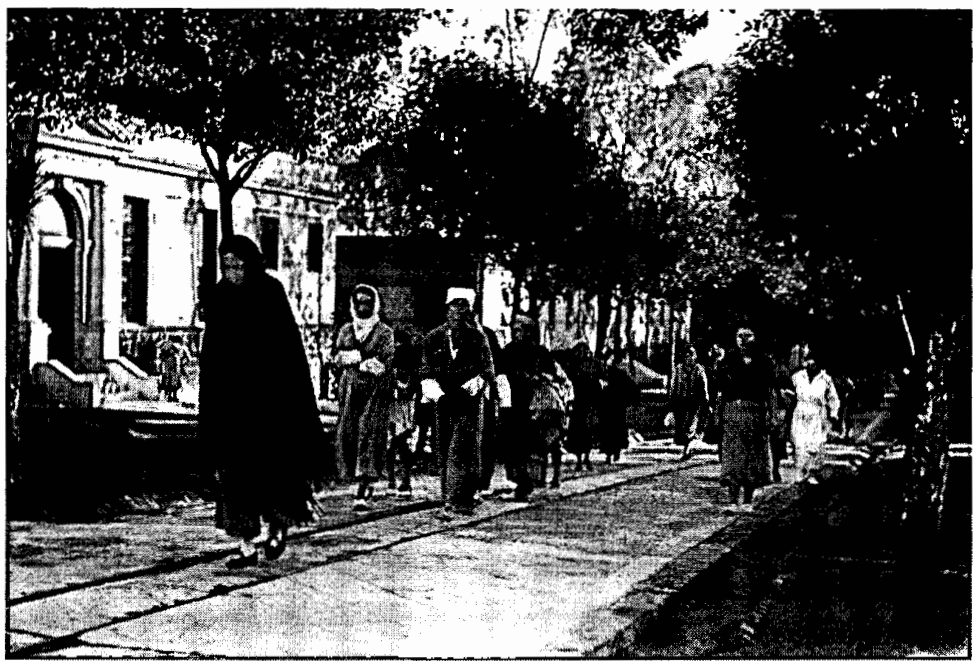

Mujeres internas caminando por los jardines de La Castañeda hacia 1930.

Fondo Casasola 1, inv. 88276, () CONACUITA-INAH-SINAFO-FOTOTECA NACIONAL.

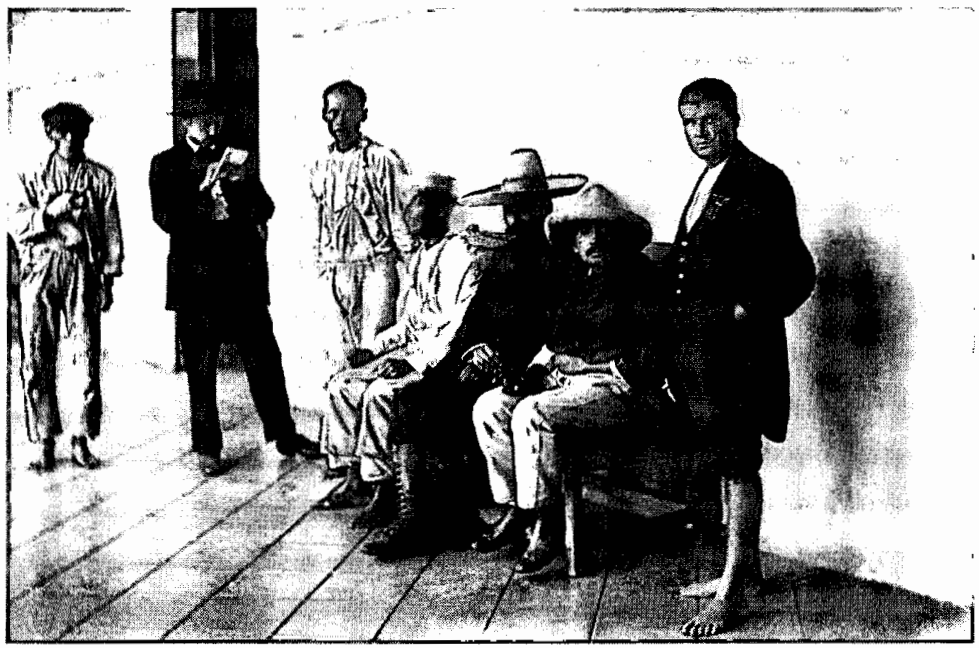

Ignacio Fernández Esperón (Tata Nacho) junto a internos durante un reportaje en el también llamado Manicomio de Mixcoac, 1924.

Fondo Casasola III, inv. 15130, $\odot$ CONACULTA-INAH-SINAFO-FOTOTECA NACIONAL. 
y mujeres residentes en el manicomio. Por último, y remarcando el carácter público de la institución, las autoridades les recordaban a los empleados que el manicomio había sido construido para el solo beneficio de los enfermos mentales, "a quienes deberían servir con la consideración que se merecía su miserable condición". ${ }^{45}$ Si algún empleado no llenaba estas altas expectativas morales, las autoridades podrían destituirlo; pero si "no trataban a los internos con consideración" podrían además acusarlo con las autoridades civiles. 46

El Reglamento Interno de 1913 estipuló reglas para proveer a los internos con la mejor asistencia psiquiátrica que el Estado podía ofrecer, manteniendo al mismo tiempo el orden administrativo de la institución y acrecentando el estatus científico de la misma. Como en otros tantos hospitales estatales del siglo XIX a escala mundial, poner a funcionar estas reglas, sin embargo, fue una tarea monumental, acaso imposible. Así entonces, en lugar de seguir derroteros preestablecidos, el manejo de la salud mental dentro de La Castañeda en realidad fue creado y recreado por las idiosincrasias de los actores que el reglamento intentaba controlar: administradores, miembros del personal médico, e internos. Los límites del orden institucional fueron acentuados, además, por el cambiante contexto social en el cual emergió el manicomio. En ese abismo que se abrió entre las reglas oficiales y la práctica cotidiana de la psiquiatría se

45 Ibid., p. 66.

46 Ibid., p. 67. formó esa manera singular y tensa de percibir y tratar la locura en el México de inicios de siglo.

\section{TOMA II: UNA INTERPRETACIÓN DESDE ADENTRO}

Si bien la organización interna de La Castañeda distaba mucho de lo estipulado en el Reglamento Interno, al pasar de los años los actores psiquiátricos que ahí convivían desarrollaron, si no un orden rígido, sí una rutina más o menos regular. Desde la mañana hasta las horas nocturnas, desde el proceso de admisión hasta la dada de alta o la muerte, los internos y los doctores designaron actividades para sí mismos -a veces en flagrante oposición a las regulaciones internas, a veces en sutil evasión de las mismas- que hicieron del manicomio nacional una institución con funciones múltiples, en ocasiones complementarias y, en otras, paradójicas. Este segundo recorrido por los pasillos de la institución captura algunos momentos significativos en la vida cotidiana del lugar, especialmente aquellos que contribuyeron a la creación de una rutina de salud mental que, en el caso de La Castañeda, estuvo marcada por el afán de proveer asistencia médica y el ímpetu de apoyar procesos más amplios de control social.

Todo empezaba a las siete de la mañana, cuando el silbato del manicomio despertaba a todo el vecindario. ${ }^{47} \mathrm{~A}$ esa hora, los administradores y el personal médico se preparaban para em-

47 Ver entrevista con Víctor Serralde en Pensado y Correa, Mixcoac, 1996, p. 38. 
pezar otro día entre los internos de $\mathrm{La}$ Castañeda. El jefe del departamento. de admisiones abría las puertas de su oficina y, una hora después, empezaba el escrutinio de los pacientes. Mientras que los primeros 848 internos que fueron admitidos en la institución el día de su inauguración -430 hombres y 418 mujeres provenientes del Hospital de San Hipólito y del Divino Salvador respectivamente- no pasaron por el procedimiento oficial, los nuevos pacientes sí lo hicieron. ${ }^{48}$ Éste incluía, primero, la presentación de documentos oficiales de identificación, una sesión de preguntas y respuestas de acuerdo con los lineamientos del cuestionario médico, y el examen físico del paciente de cuyos resultados dependería su admisión. Llevada a cabo por un médico residente, esta entrevista psiquiátrica inicial se realizaba en el cuarto de observación.

De acuerdo con el reglamento interno, tanto el Estado como la familia estaban autorizados para internar a los pacientes. Por un lado, las autoridades que podían ordenar el internamiento eran la Secretaría de Gobernación, la Beneficencia Pública, y el gobernador y jueces del Distrito Federal. Por otro lado, tanto familiares como tutores legales del enfermo, así como los enfermos mismos, estaban autorizados para solicitar admisión al establecimiento. En ambos casos, se requería de un certificado médico firmado por un doctor de la Inspección de Policía para dar

48 Datos acerca de la transferencia de internos de los hospitales coloniales a las instalaciones del Manicomio General fueron tomados de los libros de registros de la institución. inicio al proceso. De especial importancia para las autoridades del manicomio era un reporte que describiera "los defectos de conducta y la falta de adaptabilidad social que justificara el diagnóstico de enfermedad mental", un requisito que de manera indirecta definía este tipo de padecimientos como un fenómeno social disruptivo. ${ }^{49} \mathrm{Sin}$ embargo, las admisiones no siempre sucedían de acuerdo con las reglas. En "casos de emergencia" las autoridades admitían internos aun sin el certificado médico, un documento que a veces era elaborado por un residente ya cuando el paciente se encontraba dentro del establecimiento. De la misma manera, la Inspección de Policía tenía el derecho de remitir personas al asilo aun sin la orden legal, la cual se obtenía algunas veces después de aceptar al paciente. ${ }^{50}$ Además, los juicios de interdicción -una herramienta legal que se usaba en otros países para prevenir el encierro involuntario de personas sanas- eran empleados sólo en contadas ocasiones. Esto era significativo en un manicomio en que la gran mayoría de los pacientes $-86 \%$ de las mujeres y $68 \%$ de los hombres- se internaban como resultado de una orden gubernamental. ${ }^{\text {I }}$ Ciertamente, desde 1914 un despacho presidencial ordenó que el juicio de interdicción antecediera el internamiento de los pacientes de acuer-

49 "Reglamento interior del establecimiento" 1913 en AHSSA, FBP, SEH, SeMG, leg. 3, exp. 25, p. 3. so Ibid., pp. 2-3.

51 Estos datos están basados en una muestra ( 50 hombres y 50 mujeres) tomada de los libros de registro de la institución. 
do con los postulados del artículo 1390 del Código Civil Mexicano. ${ }^{52}$ Sin embargo, aun Juan B. Rojas, el jefe de la Beneficencia Pública que celebró esta medida como humanitaria y legal, encontró difícil, si no es que imposible, su funcionamiento. ${ }^{53}$ No sólo creía que el juicio de interdicción involucraba un proceso caro y lento, sino que también contendía que la protección de los derechos humanos de los internos se lograba a costa del presupuesto de la Beneficencia y de la rutina médica del manicomio. Por estas razones, sugirió que se descartara este tipo de juicios y que, en su lugar, se dejara el proceso de admisión en las manos del personal administrativo y médico de la institución. Las autoridades del manicomio apoyaron esta moción, aunque por razones distintas. Creyendo que los juicios de interdicción ponían en duda el carácter médico del establecimiento, algunos directores del manicomio llegaron al grado de increpar al procurador del Distrito Federal cuando éste intentó llevarlos a cabo. "El manicomio" le recordaba el director en 1919 ,

obedece reglas administrativas y médicas de acuerdo con las ideas modernas de beneficencia y tratamiento médico -en contra de las perspectivas antiguas que concebían al manicomio como un medio de defender a la sociedad de los dementes. Esta institución es un hospital en el cual los pacientes se admiten y se dejan

\$2 Un análisis de la legislación de los pacientes psiquiátricos en México es Sacristán, “Quién?", 1998.

53 "Juicio de interdicción", 1914, en AHSSA, FBP, SEH, SeMG, leg. 50, exp. 1, pp. 3-6. salir libremente... [los juicios de interdicción] sólo afectarían los esfuerzos por elevar esta institución del nivel de asilo al de hospital psiquiátrico. ${ }^{54}$

De esta manera, debido a las limitaciones presupuestales y a la animosidad de los médicos contra la intervención del poder judicial en su campo de acción, los juicios de interdicción se usaron únicamente con discreción durante la primera década del siglo Xx. 55 En su lugar, la 'misión dependía re-

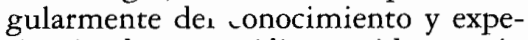
riencia de un médico residente, sin tomar mucho en cuenta los derechos humanos de los pacientes psiquiátricos.

Una vez admitidos, los internos enfrentaban un proceso de clasificación tanto médico como social basado en la información ofrecida por familiares, agentes de la policía o, cuando era posible, los pacientes mismos. Primero, los internos eran divididos de acuerdo con su estatus como libres o prisioneros y, segundo, de acuerdo con su categoría ya fuera como pensionados o indigentes. Aun cuando La Castañeda aceptaba y servía a todas las clases sociales, la mayoría de los pacientes eran claramente pobres y urbanos. Por ejemplo, en 1910, 100\% de las mujeres y

54 "Solicita al agente del ministerio público de Tacubaya una lista de asilados a quienes no se haya declarado dementes para promover la interdicción de ellos", 1919, en ibid., leg. 9, exp. 4, pp. 3-4.

55 La situación tendió a cambiar una década más tarde cuando psiquiatras de la talla de Samuel Ramírez Moreno se quejaron contra la falta de legislación en este aspecto. Véase Sacristán, "¿Quién?", 1998. 


\section{SECUENCIG}

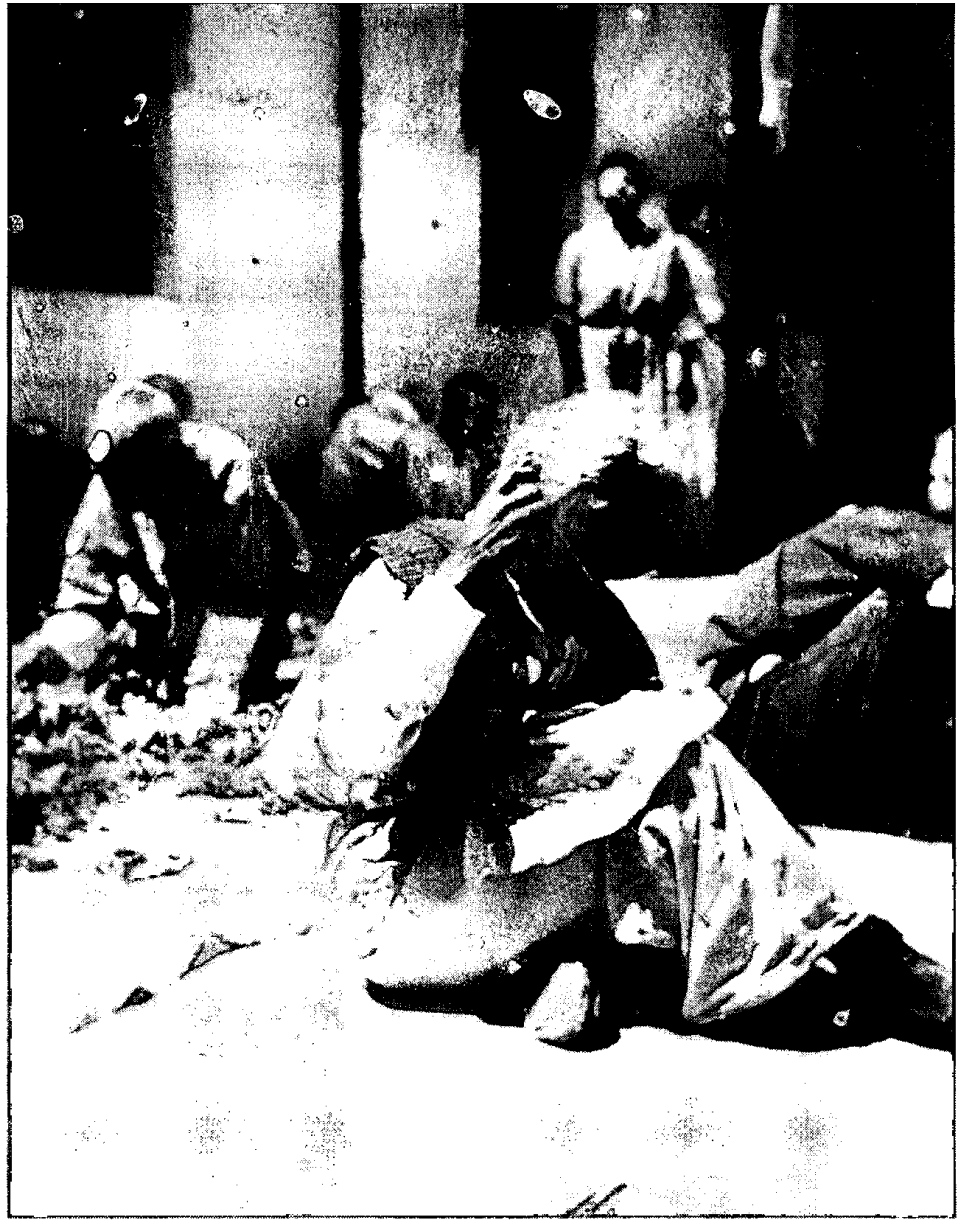

Diferentes tareas desempeñadas por los internos en los patios del manicomio, 1945. Fondo Casasola VI, inv. 296588, () CONACULTA-INAH-SINAFO-FOTOTECA NACIONAL. 
$86 \%$ de los hombres fueron admitidos como libres e indigentes. ${ }^{56}$ Los pensionados eran a su vez subdivididos en primera, segunda y tercera categorías, cada una asociada a un pago de 300 , 100 y 50 pesos mensuales respectivamente. 57

El estatus social y el diagnóstico médico también se usaban como bases para la clasificación científica de los internos dentro del manicomio -un proceso que principalmente involucraba su distribución espacial en los cinco pabellones del establecimiento. A pesar de que los diagnósticos médicos abundaban, las autoridades usaron un espectro básico de síntomas para tomar esta decisión. ${ }^{58}$ Por ejemplo, los pacientes violentos o agitados eran enviados al pabellón de los peligrosos, a donde también iban a parar los presos que requerían vigilancia especial. Los internos que padecían de condiciones crónicas iban al pabellón de tranquilos, los indigentes a la sección $A$, ubicada en la parte trasera del edificio, y los pensionados a la sección $\mathrm{B}$, localizada en los cuartos frontales que esta-

\footnotetext{
${ }^{56}$ Basado en una muestra de 100 expedientes del año de 1910.

57 "Reglamento interior del establecimiento", 1913, en AHSSA, FBP, SEH, SeMG, leg. 3, exp. 25 , p. 4.

${ }^{58}$ De hecho, los doctores de La Castañeda registraron cerca de 80 diagnósticos diferentes entre 1910 y 1920 , un número que pone de manifiesto la falta de uniformidad en el lenguaje psiquiátrico de la época. Véase Patiño Rojas y Sierra Mercado, Cincuenta, 1965, p. 5. Un análisis de la clasificación psiquiátrica es Barrios, History, 1996. También del mismo autor, "Obsessional", 1985, pp. 166-187.
}

ban rodeados de jardines. $59 \mathrm{~A}$ los que sufrían de condiciones mentales que afectaban su inteligencia se les ubicaba en el pabellón de los imbéciles, mientras que los epilépticos iban al pabellón del mismo nombre. Dentro de cada pabellón, además, los pacientes eran divididos de acuerdo con su sexo. Así entonces, la ubicación de los internos en sus pabellones particulares no sólo correspondía a consideraciones de tipo médico. De hecho, la clasificación médica, espacial y social que aseguraba el orden interno de la institución también validaba, de paso, las jerarquías que dominaban a la sociedad en general.

El papel del manicomio en la sociedad también estuvo determinado por el tipo de pacientes a quienes servía. A medida que los médicos residentes clasificaban a los internos, el jefe de admisiones apuntaba la información personal, social y médica en el libro de registro, después de lo cual abría el expediente. La información incluida en este libro revelaba que la mayoría de los pacientes del manicomio carecía de un soporte social al que recurrir en caso de necesidad, un vacío que el hospital público intentaba cubrir. A pesar de ser relativamente jóvenes -la edad promedio de los internos giraba entre los 20 y los 40 años- la gran mayoría no tenía familias $-66.5 \%$ de las mujeres y $78.5 \%$ de los hombres eran solteros o viudos- $y$, aunque residían en el Distrito Federal, un porcentaje impor-

59 Un análisis médico y social de la arquitectura del manicomio es Rivera-Garza, "Arquitectura", manuscrito. 
tante era de inmigrantes $-64 \%$ de internos masculinos y femeninos había nacido en las provincias del país. ${ }^{60}$ Los documentos también indicaban que, en términos de ocupación, las mujeres se dedicaban mayoritariamente a las labores domésticas, aunque un tercio de ellas también había participado activamente en el mercado de trabajo, especialmente como sirvientas, costureras y lavanderas. Aquellas listadas como desempleadas -alrededor de 6\%-eran por lo regular prostitutas, una profesión que uno que otro administrador prejuicioso no se atrevía a reconocer. Las ocupaciones de los internos masculinos tendían a ser más diversas. Éstas incluían una amplia variedad de oficios artesanales -zapateros, sastres, carpinteros, entre otros- así como también profesiones típicas de la clase media, tales como abogados, farmacéuticos, maestros y estudiantes. Mucho más numeroso era, sin embargo, el contingente de trabajadores industriales, como los jornaleros. ${ }^{61}$

Esta variación de géneros, clases y ocupaciones entre los pacientes determinó en gran medida la diversidad de papeles que desempeñó el Manicomio General en la sociedad mexicana de inicios de siglo. Para unos, los más destituidos, el establecimiento ciertamente era un lugar de refugio donde encontraban comida y alguna forma de cuidado ya fuera médico o de custodia de manera gratuita, lo que ratificaba el carácter público de la institución. Tal

\footnotetext{
${ }^{60}$ Basado en una muestra de 100 expedientes médicos dél año 1910.

61 Ibid.
}

fue el caso de Marino M., quien usualmente regresaba al establecimiento en periodos críticos de indigencia. ${ }^{62}$ Para otros, como Luz María S. de L., a quien su esposo trató de recluir en varias ocasiones para poder divorciarse de ella, el manicomio no era más que una cárcel donde sufría de malos tratos y aislamiento. ${ }^{63}$ Aun para otros, una proporción menor pero igualmente importante, el manicomio era una oportunidad de descargar sobre el Estado el difícil y caro cuidado de familiares con afecciones mentales. Las autoridades del manicomio, por su parte, parecían estar al tanto de esta diversidad de funciones porque, además de presentar el establecimiento como un lugar de refugio y un hospital con aspiraciones científicas, lo describían como una herramienta para liberar a la sociedad de elementos, si no abiertamente peligrosos, sí potencialmente distuptivos. Así entonces, al controlar y asistir a la población, el manicomio se colocó en una posición ambivalente y fluida dentro de un régimen social preocupado por mantener o instaurar un orden social moderno.

La rutina del hospital también involucraba la creación de mecanismos para fijar la identidad de los internos, un procedimiento que produjo un impresionante archivo visual de la locura mexicana. Cuando las autoridades terminaban de coleccionar datos en los expedientes, usualmente entregaban a los internos indigentes un uniforme

62 "Marino G.", en AHSSA, FMG; SEC (Sección Expedientes Clínicos); C (Caja) 97, exp. 67.

63 "Luz D. S. de L.", en AHSSA, FMG, SEC, C 22, exp. 63 . 
azul que, de ahí en adelante, constituiría la marca de su estado mental. Este procedimiento no se seguía, por cierto, con los pensionados. ${ }^{64}$ Después, en algunos casos y por motivos sanitarios, procedía el corte de cabello tanto de hombres como de mujeres. ${ }^{65}$ En este estado, sin sus característicos elementos que les daban identidad, los internos enfrentaban al fotógrafo y su cámara, frecuentemente por primera vez en sus vidas. ${ }^{66}$ Los gestos variaban -algunos miraban directamente al lente de la cámara, otros parecían distraídos, algunos hacían caras, otros miraban hacia el techo- pero todos eran capturados. Sin retoques, en poses frontales que carecían de cuidado, los retratos administrativos les ponían una cara humana a los expedientes que, acumulados, formaron un perfil físico de la locura en México. ${ }^{67}$

Ya recluidos, la vida cotidiana de los internos seguía un horario más o menos regular. Ciertamente, algunos internos, especialmente aquellos que no sufrían de condiciones crónicas, recibían la visita de los doctores aunque

64 "Reglamento interior del establecimiento", 1913, en AHSSA, FBP, SEH, SeMG, leg. 3, exp. 25, p. 5.

65 Material fotográfico del manicomio muestra que, aunque no muy frecuente durante los primeros años de la institución, esta práctica tendió a incrementarse con el tiempo, específicamente en los últimos años de 1910.

66 "Reglamento interior del establecimiento", 1913, en AHSSA, FBP, SEH, SeMG, leg. 3, exp. 25, p. 7.

67 Un análisis de las representaciones fotográficas de la locura en México es Rivera-Garza, "Crazy", manuscrito. no siempre entre 7:00 y 9:30 de la mañana. Algunos, de hecho, tomaban los alimentos que les enviaba la Beneficencia Pública en los comedores comunes. Otros, particularmente los internos tranquilos, trabajaban en los talleres del manicomio -las mujeres en una fábrica de rebozos y los hombres haciendo sombreros de paja - llevando a cabo actividades que, además de ser consideradas como parte de la terapia de trabajo, le generaban a la institución algo de ganancias económicas. ${ }^{68}$ Además, los internos en buenas condiciones físicas participaban en el mantenimiento del manicomio, los hombres cuidando los extensos jardines y las mujeres realizando labores domésticas, tales como el lavado de ropa o la limpieza de los pabellones. Si su condición se los permitía, no era inusual ver a internos ayudando a lavar o limpiar a compañeros de pabellón. Aunque demandante y supuestamente terapéutico, el trabajo no era la única actividad que los internos realizaban en la institución.

Como en muchos manicomios de otros países, la autoridades del manicomio mexicano intentaron ofrecer, a veces con cierto éxito, tantas actividades recreativas como les era posible buscando mejorar la condición mental

68 "Reglamento interior del establecimiento", 1913, en AHSSA, FBP, SEH, SeMG, leg, 3, exp. 25, p. 9. Diversas instituciones estatales de salud mental que carecían de fondos para administrar sedativos también acentuaron los buenos efectos de la terapia del trabajo, tal fue el caso del Willard Asylum for the Chronic Insane in the United States. Véase, Dwyer, Homes, 1987. 
de los enfermos. ${ }^{69}$ Por ejemplo, los internos estaban autorizados a recibir visitas una vez a la semana, entre 3:00 y 5:00 de la tarde, en cuartos especialmente designados para esta función. ${ }^{70}$ Aunque reguladas - los visitantes tenían que obtener una tarjeta de autorización y los encuentros eran supervisados por un guardia- las horas de visita le permitían al interno reconectarse con el mundo exterior a través de familiares o amigos. ${ }^{71}$ Algunos esperaban esa visita con ansiedad, pero otros, como Cresencia G. [sic], una viuda de 65 años que clamaba que la gente de su pueblo había envenenado a su hijo, reaccionaba con gritos y colapsos nerviosos. ${ }^{72}$ Otra actividad que, aunque censurada por las autoridades, también se llevaba a cabo dentro de los pabellones era escribir cartas, al menos entre aquellos que sabían hacerlo. Muchas veces estos escritos no llegaban a su destinatario, sino que terminaban en los expedientes de los internos. ${ }^{73}$ Este fue el caso de, entre muchos otros,

69. Román Ramírez le puso especial atención a este aspecto en su Manicomio, 1884, donde describió en gran detalle las actividades recreativas que se usaban en varias instituciones de salud mental en Estados Unidos. Una breve reseña de fuentes en este aspecto es Gamwell y Tomes, Madness, 1995.

70 "Reglamento interior del establecimiento", 1913, en AHSSA, FBP, SEH, SeMG, leg. 3, exp. 25, p. 11.

71 "Diversos, visitas", 1919, en AHSSA, FBP, SEH, SeMG, leg. 9, exp. 15.

72 "Cresencia G.", en AHHSA, FMG, SEC, C105, exp. 46.

73 "Reglamento interior del establecimiento", 1913, en AHSSA, FBP, SEH, SeMG, leg. 3, exp. 25, p. 12. los textos de Modesta B., quien en sus 35 años como interna escribió una serie de así llamados "despachos diplomáticos". ${ }^{74}$ Aunque las autoridades también censuraban material de lectu$\mathrm{ra}$, algunas novelas y uno que otro libro de poesía, especialmente los de Amado Nervo, cruzaban los muros del manicomio y entretenían a ciertos internos. ${ }^{75}$ De mayor relevancia eran, sin embargo, las actividades musicales, cinematográficas y deportivas que las autoridades ofrecían con propósitos terapéuticos. Por ejemplo, respondiendo a una petición hecha por el director del manicomio, el ejército mexicano envió una banda musical para dar conciertos cada sábado en los patios del lugar. ${ }^{76}$ Luego, el administrador solicitó una banda a la municipalidad para continuar con los conciertos porque, en su opinión, la música era "la única distracción que verdaderamente saca la melancolía de la cara de los enfermos mentales". ${ }^{77}$ Este acento en la música como terapia no disminuyó con el tiempo porque, años después, la Beneficencia Pública autorizó un presupuesto mensual de 144 pesos para estas actividades. ${ }^{78} \mathrm{Un}$ proceso similar

74 "Modesta B.", Una recreación novelada de este personaje se encuentra en Rivera-Garza, $\mathrm{Na}$ die, 1999.

75 "Reglamento interior del establecimiento", 1913; en AHSSA, FBP, SEH, SEMG, leg. 3, exp. 25, p. 12 ,

76 "Asuntos diversos. Música", 1914, en AHSSA, FBP, SEH, SeMG, leg, 4, exp, 7; p. 3.

77 "Asuntos diversos. Banda de guerra", 1916, en ibid., leg. 6; exp. 23.

78 "Diversos. Música", 1925, en ibid., leg. 12, exp. 7. 
ocurrió con las películas que se exhibían en el auditorio del manicomio, una actividad también presentada como terapéutica. No nada más los internos o los empleados sino que también algún visitante ocasional se beneficiaban con el proyector que pasaba las cintas, frecuentemente "a precios muy bajos". ${ }^{79} \mathrm{Tal}$ como en el caso de la música, el interés en las películas como herramienta de alivio no disminuyó. Años después, cuando el proyector desapareció por causas misteriosas, el director le escribió personalmente a Julio Bracho tratando de conseguir uno nuevo. ${ }^{80}$ Las autoridades también construyeron una cancha de basquetbol para proveer a los internos con la oportunidad de hacer ejercicio, otro programa designado para ayudar a disipar ideas mórbidas. Los juegos se llevaban a cabo los jueves y, tal como reportan algunos vecinos del lugar, no sólo los internos participaban en estas actividades. ${ }^{81}$ Finalmente, los internos también aprovechaban el paisaje a su alrededor. Tal como lo habían hecho los antiguos porfirianos, algunos internos caminaban por los jardines y los bos-

79 "Diversos, cinematógrafo", 1916, en ibid., leg. 6, exp. 34. Véase también entrevista con Ángel Hernández en Pensado y Correa, Mixcoac, 1996 , p. 40.

80 "Cinematográficas, exhibiciones", 1933, en AHSSA, FMG, SeA (Sección Administración) C 1, exp. 10, p. 2.

${ }^{81}$ Entrevista con Ángel Hernández en Pensado y Correa, Mixcoac, 1996, p. 40. ques que poseía el manicomio, con o sin guardia de por medio.

Desde adentro, pues, el Manicomio General era una institución de muchas texturas que funcionaba a niveles distintos, algunos de ellos complementarios y otros paradójicos. Primeramente, en tanto establecimiento público, el manicomio ayudaba con cuidado de custodia a los enfermos mentales de más escasos recursos. Segundo, como una institución estatal altamente regimentada, el manicomio contribuyó a legitimar ideas de orden y de control propias de los regímenes modernizadores. La distribución de espacio de acuerdo con el género y la clase social de los internos es un ejemplo en este aspecto. Tercero, en tanto instituto de entrenamiento, proveyó tratamiento médico a hombres y mujeres de diversas clases sociales y, a través de investigaciones personales, contribuyó a la producción de conocimiento psiquiátrico. Sin embargo, debido a limitaciones financieras y al reacomodo propio de los años revolucionarios, $\mathrm{La}$ Castañeda no era ni tan controladora como las autoridades esperaban ni tan generosa como lo predicaba la ideología de la Beneficencia Pública. De hecho, al ayudar a los necesitados, al controlar a los desubicados, y al producir conocimiento sobre las enfermedades mentales, La Castañeda se convirtió en un territorio camaleónico en el que tanto los administradores, como el personal médico y los. enfermos mismos, construyeron su propia definición de la locura y sus tratamientos. 


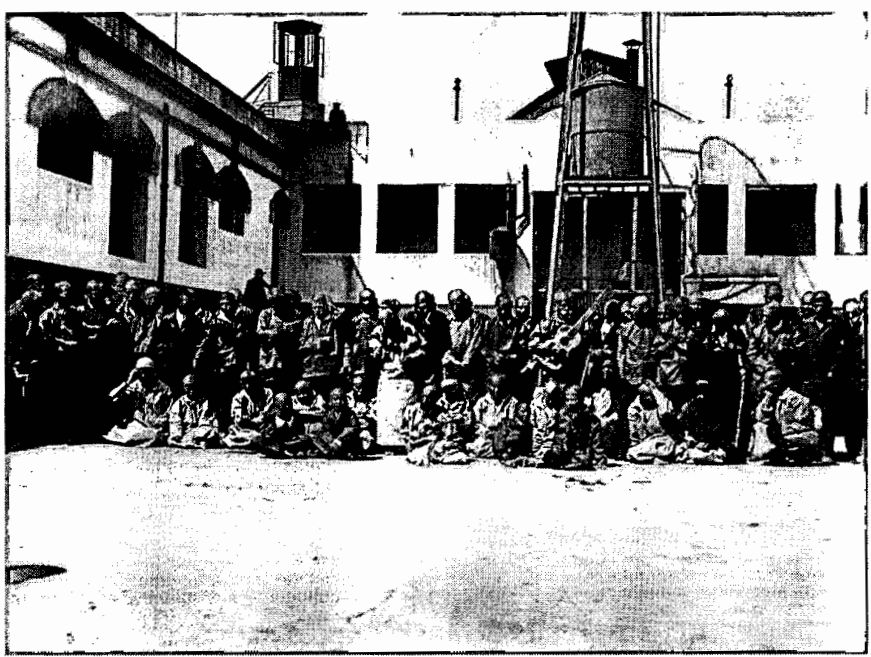

Internos en uno de los patios de La Castañeda. Arriba, a la izquierda, se aprecia el sistema de vigilancia, 1930.

Fondo Culhuacan, inv. 366983, C CONACULTA-INAH-SINAFO-FOTOTECA NACIONAL.

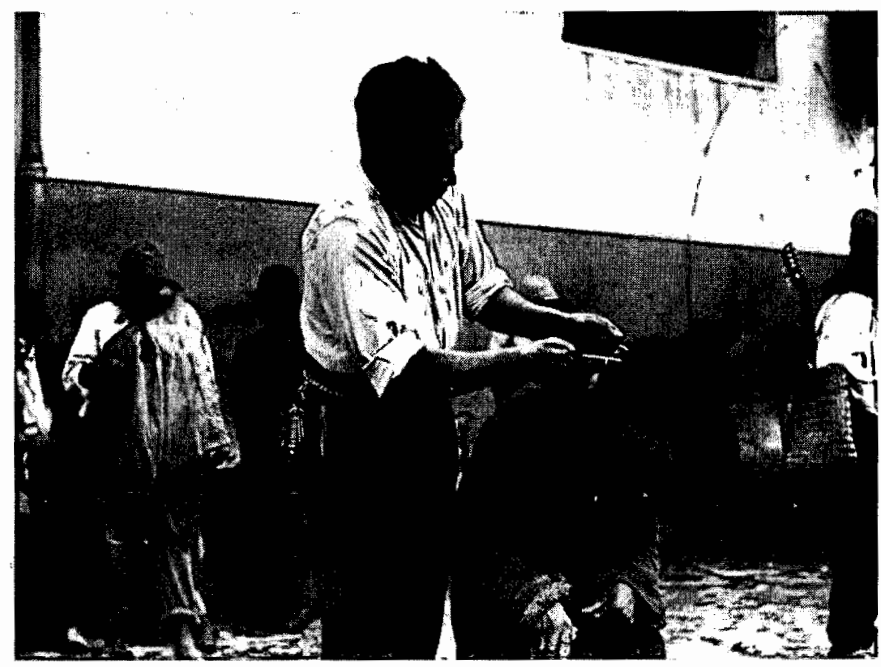

La vida cotidiana en el Manicomio de Mixcoac, 1930.

Fondo Culhuacan, inv. 366985, (-) CONACULTA-INAH-SINAFO-FOTOTECA NACIONAL. 
TOMA III: LA MUERTE DE UN PROYECTO -LA MODERNIDAD COMO CRISIS

Aunque algunos todavía recuerdan a $\mathrm{La}$ Castañeda como un edificio monumental que "ocupaba nueve cuadras completas, casi 100 mil metros, con jardines muy hermosos y pabellones destinados a condiciones distintas", el Manicomio General cambió drásticamente, y a una velocidad acaso insuperable, después de septiembre de $1910 .^{82}$ A sólo dos meses de su inaguración, en noviembre del mismo año, dio inicio la revolución mexicana, desbancando a un régimen de casi treinta años. Conforme avanzó el conflicto armado, poco quedó sin trastocarse en el país, y el Manicomio General no fue la excepción. Aunque situado en la periferia de la ciudad, La Castañeda se convirtió en otro escenario de la batalla cuando los zapatistas tomaron la institución a finales de enero de $1915 .{ }^{83}$ Para inicios de febrero, las balaceras entre zapatistas y constitucionalistas eran tan fuertes que "crearon pánico entre las familias de los empleados que trataban de evadir las balas que cruzaban el aire". ${ }^{84}$ Cuando, semanas después, los zapatistas abandonaron las instalaciones del manicomio, las autoridades no dudaron en acusarlos de robo ya que, con ellos, desaparecieron las gallinas, conejos y cabras que había en el lu-

82 Entrevista con Manuel González Santana en ibid., p. 40 .

83 "Diversos. La ocupación zapatista", en AHSSA, FBP, SEH, SeMG, leg. 4, exp. 28.

84 "Diversos. Tiroteo zapatista", en ibid., leg. $4, \exp 19$, p. 1. gar. ${ }^{85}$ Más signficativo fue el hecho de que tres internos peligrosos se convirtieron en soldados zapatistas de un momento a otro y abandonaron el hospital para seguir las órdenes del general Sandoval, una decisión que también tomó Salvador Gutiérrez, un profesor de la institución. ${ }^{86}$ Aunque la ocupación militar sólo afectó a algunas secciones de La Castañeda -las residencias de los médicos, un par de pabelloneslos daños fueron menores en comparación con el deterioro masivo del establecimiento. Ciertamente, sin el apoyo económico ni la inversión política que le dio vida, el Manicomio General enfrentó mayores dilemas económicos, los que, al afectar sus ramas tanto administrativas como médicas, forzaron a una gradual redefinición de la institución estatal en su conjunto.

Uno de los primeros retos fue el sobrecupo. En 1910, cuando el manicomio abrió sus puertas al público, había 1330 camas en la institución -730 reservadas para mujeres y 600 para hombres. ${ }^{87}$ Aun cuando este cálculo se basó en patrones demográficos locales y nacionales, pronto la realidad le demostró a las autoridades que habían cometido un grave error. Para diciembre de 1910, había ya 1004 internos y, para 1911, el número de camas fue insuficiente. Las autoridades enfrentaron otro dilema porque, aun cuando reconocían que tenían que reducir el número de pacientes, estaban al tanto de que la situación había sido provocada

85 Ibid., p. 2.

86 "Diversos. Ocupación zapatista y constitucionalista", en ibid., leg. 4, exp. 37.

87 Patiño y Sierra Mercado, Cincuenta, p. 5. 
por los mismos principios de beneficencia que le daban sentido. Primeramente, las reglas internas mandaban que el manicomio aceptara a toda persona que necesitara ayuda psiquiátrica sin importar edad, sexo, religión y, de mayor importancia, situación económica. Segundo, en tanto institución nacional, La Castañeda estaba forzada a recibir pacientes no sólo provenientes de la ciudad sino de todo el país y, a veces, hasta de naciones extranjeras. Finalmente, debido a que la mayoría de los pacientes sufría de condiciones crónicas, éstos permanecían en las instalaciones por largos periodos, agravando los problemas de espacio y de atención médica. Así entonces con pocas alternativas disponibles, las autoridades comúnmente optaban por pedir a la $\mathrm{Be}$ neficencia Pública que aumentara su presupuesto -peticiones que, también comúnmente, no eran respondidas.

A pesar de que el manicomio permaneció abierto durante la etapa armada de la revolución, el poco presupuesto y la negligencia gubernamental pronto afectaron la estructura física y la calidad de los servicios que prestaba el manicomio. Por ejemplo, para 1916, los inspectores de la Beneficencia notaron que los internos no llevaban ropas adecuadas y que comían bolillos que no "llegaban a pesar ni 40 gramos". 88 Hacia 1920, los problemas no sólo concernían a la ropa y la comida, sino que incluían la falta de colchones -razón por la cual los internos dormían sobre la estructura de hierro de las camas de hospital-, carencia de electrici-

88 "Informe de inspectores", 1916, en AHSSA, FBP, SD; SeDG; leg. 18; exp. 21; p. 132. dad y medicamentos básicos, goteras en los techos, deterioro de la duela de los pisos, puertas y ventanas de la mayoría de los edificios. ${ }^{89}$ Para agravar las situación, como el manicomio carecía de seguridad, estaba expuesto a los ataques del público, lo cual llegó a pasar en algunas ocasiones. 90 Sintiendo que éste era terreno fértil para noticias sensacionalistas, algunos periodistas visitaron el establecimiento y lo describieron como una ruina, una institución

en completo estado de desolación que carecía de higiene en la cocina y proporcionaba comidas escasas y malas a los internos, además de darles ropas miserables a los indigentes. [En suma] los pabellones, los cuartos de aislamiento, los jardines, las calles y los patios están en completo olvido. ${ }^{91}$

A pesar de que las autoridades intentaron limitar el acceso de los periodistas, especialmente si éstos cargaban cámaras fotográficas, las noticias de desorden, desolación y llano terror continuaban apareciendo en los periódicos. ${ }^{92}$ En poco tiempo, los periodistas se empezaron a referir a La Castañeda como una "colonia penal" donde los enfermeros castigaban a los enfermos a golpes y los guardias comerciaban con

89 "Informe del manicomio", 1920, en AHSSA, FBP, SEH, S:MG, leg. 10, exp. 24.

90 "Diversos, seis individuos en estado de ebriedad querían pasar por la fuerza", 1919, ibid., leg. 9, exp. 6.

91 "Diversos, nota de El Universal", 1918, en ibid., leg. 8, exp. 27.

92 "Diversos, un reporte de El Democrata", 1919, en ibid., leg. 10, exp 11, p. 1. 
cieron salarios mayores a "los jóvenes elementos, verdaderos amantes de esta difícil e ingrata ciencia, que gustosos beberían de la fuente del conocimiento que dan la observación y la experiencia". ${ }^{101}$ La situación del personal médico, sin embargo, no mejoró.

La posibilidad de proveer servicios médicos adecuados también se vio afectada por el reducido número de enfermeros y guardias. A sólo dos años de su inauguración, cada enfermero del manicomio cuidaba un promedio de 150 internos en distintos pabellones. Simultáneamente, un total de 1024 internos eran supervisados por 86 guardias - una cantidad que, de acuerdo con el director, tendría que duplicarse si se quería proveer atención adecuada. ${ }^{102}$ Estas condiciones se mantuvieron estables a lo largo de la vida del manicomio. Si a estos números se le añade el hecho de que tanto enfermeros como guardias carecían por lo regular de entrenamiento o vocación, es fácil imaginar la negligencia y la violencia que los periódicos se empeñaban en mostrar como ciertas.

Pero estas descripciones descarnadas del Manicomio General no sólo aparecían en diarios. A pesar de que las autoridades no cesaban de cuestionar la veracidad de los artículos, los reportes de los inspectores de la Beneficencia Pública confirmaban su contenido. Cargos contra la calidad y la cantidad de comida ofrecida en el manicomio

101 "Proyecto de organización", 1920, en AHSSA, FBP, SEH, SeMG, leg, 10, exp. 24, p. 10.

102 "Presupuesto", 1912, en AHSSA, FBP, SEH, SeMG, leg. 2, exp. 6, p. 8. no cesaron durante los años veinte. ${ }^{103}$ De hecho, hacia el final de la década, la inspectora Elisa P. viuda de Guijarro no sólo se detuvo a describir el sabor a estaño que impregnaba las comidas, sino que también contó con lujo de detalles

el deterioro de los pabellones, especialmente los de hombres, de donde tanto puertas como ventanas han desaparecido. La carnicería y la panadería no son higiénicas y requieren, como todo el establecimiento, remodelación. Todos los comedores necesitan bancas, así como los pasillos porque los internos se sientan directamente sobre los pisos. ${ }^{104}$

La inspectora también se dio cuenta de que la insuficiencia de camas en el pabellón de epilépticas forzaba a las internas a dormir juntas, lo que era, en su opinión, "antihigiénico, inmoral, y peligroso". " ${ }^{105}$ Reproduciendo esta queja, la paciente Modesta B. detalló en sus escritos que la falta de un lugar privado hacía que las internas "anduvieran por ahí oliendo las partes húmedas". ${ }^{106}$ Las irregularidades no paraban ahí. Dos años más tarde, el inspector Gabriel Cházaro registró situaciones involucrando el asesinato de un interno, perpetrado supuestamente por dos guardias del manicomio. ${ }^{107} \mathrm{Tal}$ como lo resumió el doctor José Gómez Robleda, jefe del De-

103 "Diversos. Informe", 1928, en AHSSA, FBP, SEH, SeMG, leg, 13, exp. 1.

104 "Diversos. Informe", 1929, en ibid., leg.

14 , exp. 14, p. 5 .

los Ibid., p. 3.

106 "Modesta B.", en AHSSA, FMG, SEC, C 105, exp. 16 (6339).

107 "Actas", 1931 en AHSSA, FBP, SEH, SeMG, leg. 17 , exp. 1, p. 1. 
partamento de Observación, el manicomio "se encontraba en total estado de negligencia, careciendo de los mínimos recursos requeridos para funcionar aun de manera mediocre". ${ }^{108}$ Para ilustrar sus ideas, el doctor incluyó fotografías en blanco y negro donde la acumulación de basura, el graffiti en las paredes, y los baños destruidos no dejaban lugar a la duda. La Castañeda era, ciertamente, un lugar desesperado. Los límites del proyecto modernizador que le dio vida no podían ser más evidentes.

A pesar de que algunas autoridades intentaron salvar la situación con cierta vehemencia, todos ellos responsabilizaron a la falta de recursos por la ausencia de cambios. Sin embargo, aunque reales, los factores externos eran sólo uno de los muchos elementos en juego dentro de este proceso. Una plétora de factores internos, especialmente los relacionados con la tensa relación entre internos, burócratas y médicos, también intervinieron para crear la situación. Aunque dentro de La Castañeda pocas veces se llevaron a cabo motines $\mathrm{u}$ otra forma de protesta activa -situaciones por lo demás comunes en otros hospitales públicos incluyendo, notoriamente, al Hospital Morelos donde prostitutas secuestradas frecuentemente organizaron pronunciamientos contra las autoridades médicas- los internos del manicomio encontraron otras estrategias para evadir, si no confrontar, el sistema hospitalario. ${ }^{109}$ Esp. 1.

108 "Informe", 1931, en ibid., leg. 16, exp. 1,

109 Un análisis de las prostitutas en el Hospital Morelos es Rivera-Garza, "Criminalization", en prensa. taba, por ejemplo, el contacto diario que, a pesar de las regulaciones, se registraba entre internos ya fuera en los pabellones o en los talleres de trabajo. También estaba la lentitud con la que los internos que podían trabajar realizaban sus actividades, una actitud que eventualmente acabó con las iniciativas de terapia de trabajo implementadas en la institución. En 1929, de hecho, el doctor Hernán Valverde León reportaba que los internos se quejaban continuamente de que las autoridades "no les daban nada a cambio de su trabajo" lo que constituía una crítica latente en contra del sistema de trabajo no pagado en el que eran forzados a participar. 110 Aún más, ahí estaba siempre la oportunidad de dejar la institución sin trámites administrativos de por medio. A pesar de que las regulaciones eran muy claras al respecto -se requería la firma de un doctor para autorizar un altaalgunos internos se iban del manicomio sin la sanción apropiada. El tamaño mismo del establecimiento, su ubicación y diseño arquitectónico, así como también la carencia de personal de policía, facilitaban esta opción. Muchos aprovechaban sus permisos de salida, ya sea para visitar parientes o tomar una caminata, para no regresar a sus pabellones. Este fue el caso de, entre otros, Altagracia G., cuya alta fue obtenida debido al hecho de que "la enferma no regresó al hospital después de un permiso de quince días". $111 \mathrm{Al}$ -

110 "Diversos. Trabajos y labores de los enfermos", 1929, en AHSSA, FBP, SEH, SeMG, leg. 14, exp. 7, p. 2.

1.1 "Altagracia G.", en AHSSA, FMG, SEC, C 106, exp. 12 (6443), p. 2. 
gunos más, como Marino M., permanecieron en el manicomio más o menos a voluntad, entrando y saliendo de acuerdo con necesidades propias. ${ }^{112}$ Aun los que se quedaban dentro de las celdas de su enfermedad crónica causaban problemas inevitables, aunque sólo fuera por su creciente número. Las estrategias que los internos encontraron para sobrevivir dentro de La Castañe$\mathrm{da}$, pues, eran variadas y, acaso más dinámicas y menos rígidas de lo que las autoridades y la prensa amarillista suponían.

\section{ALGUNAS RESONANCIAS TEÓRICAS: LA MODERNIDAD DESDE ADENTRO (DE UN MANICOMIO)}

Los inspectores de la Beneficencia Pública continuamente confirmaron el estado "triste" y "deplorable" que imperaba en La Castañeda. A medida que pasaron los años, estos reportes se volvieron rutinarios. Sin embargo, aun cuando los documentos oficiales y la prensa presentaban al manicomio, a veces inconscientemente y otras con total intención, como una "colonia penal" donde enfermeros enloquecidos y malévolos guardias ejercían un dominio total sobre los internos - una visión que hasta hace poco imperó en los análisis de manicomios a escala mundial-, un examen de la rutina cotidiana desde dentro del hospital parece indicar que la realidad era un poco más compleja. Ciertamente, La Castañeda estaexp. 67 . ba muy lejos de ser la institución perfecta que daban a entender las regulaciones internas $\mathrm{y}$, tal como muchas autoridades lo adujeron, la falta de recursos era una de las causas más importantes de esta situación. Sin embargo, los crecientes problemas que plagaron a la institución también fueron el resultado de la interacción activa y desestabilizante que se desarrolló entre los actores psiquiátricos. Confirmando algunos de los descubrimientos que han hecho autores llamados revisionistas, este análisis histórico revela que la rutina de salud mental desarrollada en el manicomio mexicano era multifacética y paradójica. Luego entonces, en su intención de recluir y ayudar a los enfermos mentales de todas las clases sociales, el manicomio moderno cumplió funciones de cárcel para algunos y lugar de refugio para otros. Si bien los prejuicios de clase y de género estuvieron presentes en los procesos de admisión, distribución espacial y tratamientos médicos ofrecidos en el lugar, las autoridades también estaban al tanto de que las naciones modernas "eran medidas por la extensión de sus obras públicas". ${ }^{113}$ Esta convulsionada interacción de agendas, objetivos y actores ilumina la ambivalencia fundamental de este proyecto modernizador así como también su naturaleza relacional -elementos que se acentuaban por darse en una institución que se ubicaba física y metafóricamente en las periferias del régimen. En ningún lado es esto más evidente que en los tenaces

\footnotetext{
113 Pereyra y Romero, "Exposición", 1898,
} p. $88-94$. 


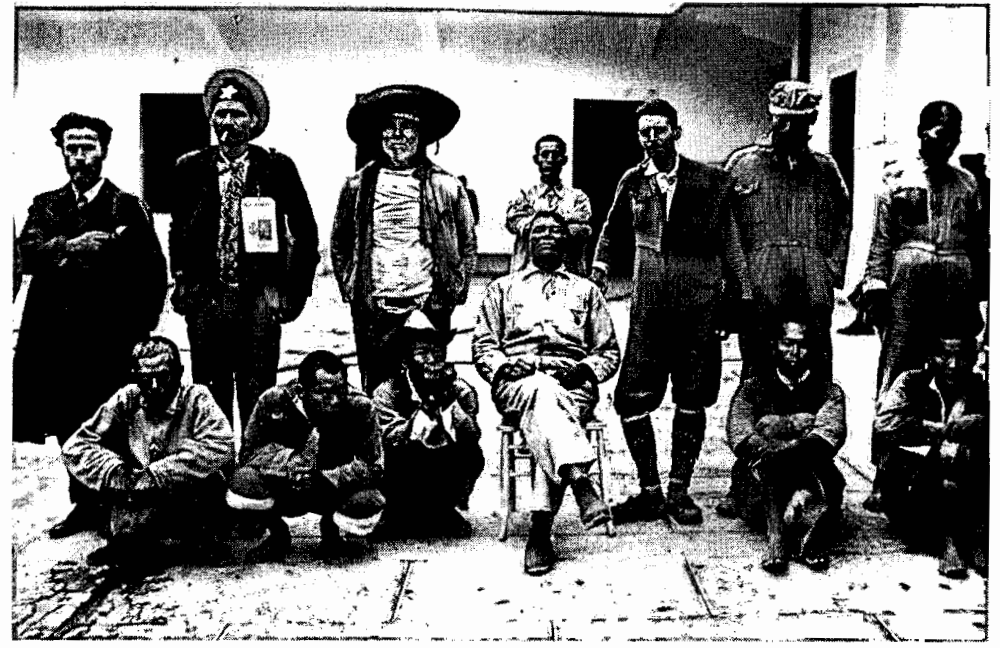

Internos en uno de los pabellones de La Castañeda hacia 1930.

Fondo Casasola II, inv. 143734, (O CONACULTA-INAH-SINAFO-FOTOTECA NACIONAL.

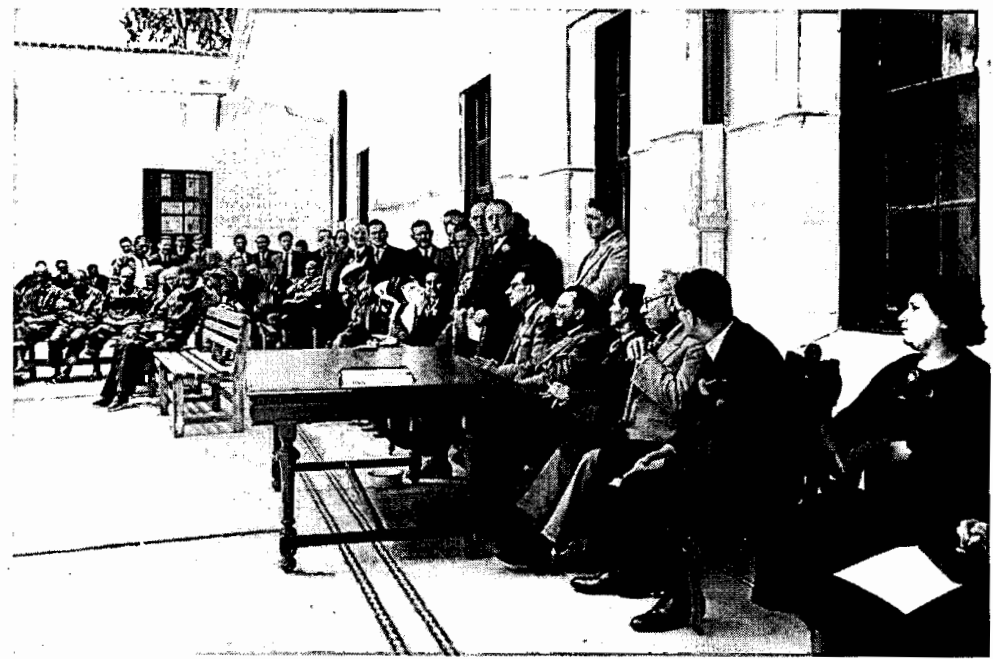

Inauguración de nuevos pabellones con motivo de la remodelación de La Castañeda, 1935.

Fondo Culhuacan, inv. 367650, (O) CONACUITA-INAH-SINAFO-FOTOTECA NACIONAL. 
reintegrado a la sociedad o pacientes psiquiátricos que no requirieran cuidado intensivo. ${ }^{119}$ Estas medidas intentaron reducir la carga de La Castañeda, pero no tenían la intención de reemplazarla. Sin embargo, esto fue exactamente lo que empezó a suceder desde 1965 en que, bajo el título de Operación Castañeda, la Secretaría de Salud y Asistencia ordenó la clausura del Manicomio General y la construcción de una serie de hospitales designados para sustituirlo. Estos incluían un hospital para pacientes mentales graves con 600 camas, un hospital para pacientes infantiles con 200 camas, tres hospitales rurales cada uno con 500 camas, y dos casas hospital para pacientes incurables con 250 camas respectivamente. ${ }^{120}$ Después, ladrillo por ladrillo, el Manicomio General fue desmantelado, literalmente deconstruyendo una larga zaga de salud mental en México. ${ }^{121}$

\section{ARCHIVOS}

AHSSA Archivo Histórico de la Secretaría de Salubridad y Asistencia.

\section{BIBLIOGRAFÍA}

-Bachrach, Leona, "Asylum and Chronically Ill Psychiatric Patients", American Journal of Psychiatry, núm. 14, 1984, pp. 975-978. 5-6.

119 "Edmundo Buentello", 1932-1966, pp.

120 Calderón, "Hospitales", p. 121.

121 La fachada del manicomio, aparentemente reconstruida de acuerdo con la original, se encuentra en una población cercana a Amecameca.
-Barrios, German E., The History of Mental Symptoms: Descriptive Pathology since the Nineteenth Century, Cambridge University Press, Cambridge, 1996.

- "Obsessional Disorders during the Nineteenth Century: Terminological and Classificatory Issues" en W. F Bynum, Roy Porter y Michael Shepard, The Anatomy of Madness. Essays in the History of Psychiatry, vol. 1. People and Ideas, Tavistock Publications, Londres y Nueva York, 1985, pp. 166-187.

-Borges, Dain, "'Puffy, Ugly, Slorhful and Inert': Degeneration in Brazilian Social Thought, 1880-1940", Journal of Latin American Studies, núm. 23, 1993, pp. 235-256.

-Buentello, Edmundo, "Orígenes y estado actual del manicomio de la Castañeda", Asistencia. Publicación mensual de la Beneficencia Pública, vol. 2, núm. 3, 1936.

-Calderón Narváez, Guillermo, "Hospitales psiquiátricos de México. Desde la colonia hasta la actualidad", Revista Mexicana de Neurología y Psiquiatría, vol. 7, núm. 3, 1966, pp.115-116.

- "Notas para la historia del Manicomio General de México, década de los 40's", Archivo del Instituto Nacional de Neurología y Neuracirugía, vol. 1, núm. 3, 1996, pp. 198-207.

-Digby, Anne, Madness, Morality and Medicine: A Study of the York Retreat 17691914, Cambridge University Press, Cambridge, 1985 .

-Dowbiggin, Ian R., Keeping America Sane: Psychiatry and Eugenics in the United States and Canada, 1880-1940, Cornell University Press, Ithaca, Nueva York, 1997.

- Inberiting Madness. Professsionalization and Psychiatric Knowledge in Nineteentb-Century France, University of California Press, Berkeley, 1991.

-Dwyer, Ellen, Homes for the Mad. Life Inside Two Nineteentb-Century Asylums, Rut- 
gers University Press, New Brunswick y Londres, 1987.

-Farmer, Paul, "The Birth of the Klinik: A Cultural History of Haitian Professional Psychiatry" en Atwood D. Gaines, (coord.), Etbnopsbychiatry. The Cultural Construction of Professional and Folk Psychiatrists, State University of New York, Nueva York, 1992.

-Foucault, Michel, Madness and Civilization: A History of Insanity in the Age of Reason, Random House, Nueva York, 1965.

- The History of Sexuality. An Introduction, Vintage, Nueva York, 1978, vol. I.

-Gamwell, Lyny Nancy Tomes, Madness in America. Cultural and Medical Perceptions of Mental Illness Before 1914, Cornell University Press, Ithaca, 1995.

-Goffman, Erving, Asylums: Essays on the Social Situation of Mental Patients and Other Inmates, Doubleday \& Anchor, Nueva York, 1961.

-Goldberg, Ann, Sex, Religion, and the Making of Modern Madness. The Eberbach Asylum and German Society 1815-1849, Oxford University Press, Nueva York, 1999.

-Goldstein, Jan, Console and Classify. The French Psychiatric Profession in the Nineteenth Century, Cambridge University Press, Cambridge, 1987.

-Grob, Gerald, Mental Institutions in America: Social Policy to 1875, Macmillan, Nueva York, 1973.

-Guerrero, Julio, La génesis del crimen en México: ensayo de psiquiatría social, Imprenta de la viuda de Ch. Bouret, México, 1901.

-Gutiérrez Nájera, Manuel, "El Pobrecito Criminal" en Boyd Carter y Mary Carter, Manuel Gutiérrez Nájera. Escritos inéditos de sabor satírico "Plato del día", University of Missouri Press, Columbia, 1972.

-Johns, Michael, The City of Mexico in the Age of Diaz, University of Texas Press, Austin, 1997.
-Joseph, Gilbert y Daniel Nugent (coords.), Everyday Forms of State Formation. Revolution and the Negotiation of Rule in $\mathrm{Mo}$ dern Mexico, Duke University Press, Durham, 1994.

-Miguel Macedo, La criminalidad en México: medios de combatirla, Oficina Tipográfica de la Secretaría de Fomento, México, 1897.

-Morales Pereyra, Samuel y Antonio Romero, "Exposición y proyecto para construir un manicomio en el Distrito Federal" en Memorias del Segundo Congreso Pan-Americano verificado en la ciudad de México, del 16 al 19 de noviembre de 1896, Hoeack y Compañía Impresores y Editores, México, 1898, pp. 888-896,

-Patiño Rojas, José Luis e Ignacio Sierra Mercado, Cincuenta años de psiquiatría en el Manicomio General, Secretaría de Salud/Archivo Histórico, México, 1965.

-Pensado, Patricia y Leonor Correa, Mixcoac. Un barrio en la memoria, Instituto Mora, México, 1996.

-Plotkin, Mariano, "Freud, Politics, and the Porteños: the Reception of Psychoanalysis in Argentina", Hispanic American Historical Review, vol. 77, núm. 1, 1997, pp. 45-74.

-Ramírez, Román, El manicomio. Ensayo escrito por comisión del ministro de Fomento, Oficina Tipográfica de la Secretaría de Fomento, México, 1884.

, Resumen de medicina legal y ciencias conexas para uso de los estudiantes de las escuelas de derecho, Oficina Tipográfica de la Secretaría de Fomento, México, 1901.

-Ramírez Moreno, Samuel, "Anexos psiquiátricos en los hospitales generales", $R e$ vista Mexicana de Psiquiatría, Neurología $y$ Medicina Legal, vol. xIII, núm. 76, 1940.

-Rivera-Garza, Cristina, Mad Narratives: Psychiatrists and Inmates Debate Gender, Class, and the Nation. Mexico, 1910-1930, Nebraska University Press (en prensa). 
, Nadie me verá llorar, Tusquets/ CNCA, México, 1999.

-, "The Criminalization of the Syphilitic Body. Prostitutes, Health Crimes, and Society in Mexico, 1867-1930" en Carlos Aguirre y Joseph Gilbert, Law, Crime and Punishment in Latin American History. Selected Essays, Duke University Press, Durham, 2001.

- "The Crazy Look: Portraits of the Mentally Ill in Porfirian Mexico", manuscrito.

- , "An Architecture of Mental Health: the Construction of the General Insane Asylum La Castañeda, Mexico 18841910", manuscrito.

-Rodríguez Kuri, Ariel, Una experiencia olvidada. El ayuntamiento de México: polititica y gobierno, 1876-1912, El Colegio de México/UAM-Azcapotzalco, México, 1996.

-Rothman, David, The Discovery of the Asylum. Social Order and Disorder in the Early Republic, Little Brown, Boston, 1980.

-Ruiz López, Ignacio y Diana Morales Heinen, "Los primeros años del Manicomio General de la Castañeda (1910-1940)", Archivo del Instituto Nacional de Neurología y Neurocirugía, vol. 1, núm. 2, 1996, pp. 124129.
-Roumagnac, Carlos, Por los mundos del delito. Los criminales de México. Ensayo de psicología criminal, El Fénix, México, 1904.

-Ruiz Zevallos, Augusto, Psiquiatras y locos. Entre la modernización contra los Andes y el nuevo proyecto de modernidad. Perú: 18501930, Instituto Pasado y Presente, Lima, 1994.

-Sacristán, María Cristina, “Quién me metió en el manicomio? El internamiento de enfermos mentales en México, siglos XIX y xx", Relaciones. Estudios de Historia y sociedad, vol. xIX, núm. 74, 1998, pp. 201-233.

-Sadowsky, Jonathan, Imperial Bedlam. Institutions of Madness in Colonial Southwest Nigeria, University of California Press, Berkeley, 2000.

-Szaz, Thomas, The Myth of Mental Illness, Harper \& Row, Nueva York, 1961.

-Torres, Agustín, "Estudio y tratamiento de los enajenados", Revista de la Beneficencia Pública, núms. 34-35, 1917, pp. 55-57.

—_, "El Manicomio General," Revista de la Beneficencia Pública, núms. 34-38, 1917, pp. 30-32.

-Wright, David y Roy Porter, The Confinement of the Insane. International Perspectives, Cambridge University Press, Cambridge, 2001.

Por la SALUd MENTAL de La NACIÓN... 